\title{
HISTORICAL PERSPECTIVES
}

\section{LEWIS H. SARETT}

Senior Vice-President for Science and Technology, Merck \& Co., Inc., PO Box 2000, Rahway,

New Jersey 07065

NoTHING could please me more than to be with you at this meeting and to have the privilege of introducing this symposium. The time does not seem so very long ago since I went frequently to meetings such as this. In those days, and I speak of the 1950s, the pain of inflammation was treated with aspirin, phenacetin, and phenylbutazone. These were, and are, useful analgesics but they clearly have their limitations. Indomethacin was just starting its long path from the laboratory to the clinic, and it was by no means clear that the early versions of this molecule would have clinical utility, especially since the animal models in those days were of such speculative value.

At this stage fate intervened in the form of a letter from Dr Walter Bauer, Professor of Rheumatology at Harvard Medical School and the 'grey eminence' of American rheumatologists. On 12 Feburary, 1953, he wrote to Dr Randolph Major, our then Director of Research. His request asked if Merck could synthesize a better aspirin. He thereby eliminated new corticosteroids from consideration but still left a good deal of room for speculation. As a consequence I paid a visit to Cambridge and tried to clarify whether Dr Bauer had a pharmacological or a chemical equivalent of aspirin, or perhaps both, in mind. After much discussion and cogitation, we concluded that our goal should be a salicylic acid molecule whose pharmacological properties were superior in terms of safety and efficacy to aspirin itself.

Pursuit of this objective required a strong dose of optimism, since such an abundance of salicylates had been synthesized and tested without any great progress. After all, extracts of willow bark had been used for a great variety of agues and so-called 'intermitting disorders' from the earliest of times. Even the effectiveness of salicylates as a specific remedy for rheumatic fever was reported in the Lancet (Maclagan, 1876). With the advent of synthetic chemistry, salicylic acid became a medicinal prototype for which improvements were sought early and often. In fact, there are few prototypes which have so steadfastly refused to allow themselves to be improved on as aspirin. Nonetheless, through persistence and good fortune, a group of collaborators succeeded in synthesizing a new molecule which was brought through development and into the clinic. May I express the hope that, as you weigh the data, you will feel that it approaches what Dr Bauer had in mind.

\section{Reference}

MACLAGAN, T. (1876). Lancet, i, 342. 